cellular components. Clin Pediatr 20:31

23. Pittman JG, Martin DB 1966 Fatty acid biosynthesis in human erythrocytes. J Clin Invest 45:165

24. Radin NS 1981 Extraction of tissue lipids with a solvent of low toxicity. In: Lowenstein JM (ed) Methods in Enzymology, Vol 72, Academic Press, New York, p 5-7

25. Romsos DR, Miururi KL, Lin P-Y, Leveille GA 1978 Influence of dietary fat, fasting and acute premature weaning on in vivo rates of fatty acid synthesis in lactating mice. Proc Soc Exp Biol Med 159:308

26. Russo J, Furmanski P, Bradley R 1976 Differentiation of normal human mammary epithelial cells in culture: an ultrastructural study. Am $\mathbf{J}$ Anat 145:57

27. Russo J, Furmanski P, Rich MA 1975 An ultrastructure study of normal human mammary epithelial cells in culture. Am J Anat 142:221

28. Smith S 1980 Mechanism of chain length determination in biosynthesis of milk fatty acids: a review. J Dairy Sci 63:337

29. Smith S 1981 Long-chain fatty acyl-S-4'-phosphopantetheine-fatty acid syn- thase thioester hydrolase from rat in: Lowenstein JM (ed) Methods in Enzymology, Vol 71, Academic Press. New York, p 181-188

30. Smith S, Gagne HT, Pitelka D, Abraham S 1969 The effect of dietary fat on lipogenesis in mammary gland and liver from lactating and virgin mice. Biochem J 115:807

31. Smith S, Libertini LJ 1979 Specificity and site of action of a mammary gland thioesterase which releases acyl moieties from thioester linkage to the fatty acid synthetase. Arch Biochem Biophys 196:88

32. Smith S, Pasco D, Nandi S 1983 Biosynthesis of medium-chain fatty acids by mammary epithelial cells from virgin rats. Biochem $J$ 212:155

33. Smith S, Pasco D, Pawlak J, Thompson BJ, Stampfer M, Nandi S 1984 Thioesterase II, a new marker enzyme for human cells of breast epithelial origin. J Natl Cancer Inst 73:323

34. Taylor-Papadimitriou J, Shearer M, Tilley R 1977 Some properties of cells cultured from early-lactation human milk. J Natl Cancer Inst 58:1563

35. Thompson BJ, Stern A, Smith S 1981 Purification and properties of fatty acid synthetase from a human breast cell line. Biochim Biophys Acta 662:125

\title{
Surfactant Treatment and Ventilation by High Frequency Oscillation in Premature Newborn Rabbits: Effect on Survival, Lung Aeration, and Bronchiolar Epithelial Lesions
}

\author{
ROLAND NILSSON, PER BERGGREN, TORE CURSTEDT, GERTIE GROSSMANN, \\ GUNNAR RENHEIM, AND BENGT ROBERTSON \\ Departments of Pediatric Pathology and Pediatrics, St. Görans Hospital, Stockholm, Department of Clinical \\ Chemistry, Karolinska Hospital, Stockholm, and Ventilator Division, Research and Development Department,
} Siemens-Elema, Solna, Sweden

\begin{abstract}
Premature rabbit neonates delivered at gestational age 27 days were ventilated by high frequency oscillation for $60 \mathrm{~min}$ with $100 \% \mathrm{O}_{2}$, using a frequency of $7-8 \mathrm{~Hz}, 50 \%$ inspiration time and mean airway pressures of $6-8 \mathrm{~cm} \mathrm{H}_{2} \mathrm{O}$. Twenty-five animals received bovine surfactant $(2 \mathrm{ml} / \mathrm{kg}$ body weight; phospholipid concentration $85-100 \mathrm{mg} / \mathrm{ml}$ ) in the tracheal cannula before onset of ventilation, and 22 littermates served as controls. In the surfactant-treated group, average tidal volume was about 10 times larger than in controls, yet only $15 \%$ of the estimated dead space. Judged from ECG recordings, the treated animals also had a much higher survival rate: 96 versus $5 \%(p<0.001)$. Morphometrically, mean alveolar volume density was increased in the surfactant-treated animals in comparison with controls: $0.65 \pm 0.08$ versus $0.37 \pm 0.08(\overrightarrow{\mathrm{x}} \pm \mathrm{SD} ; p<0.005)$. Bronchiolar epithelial lesions were found in all control animals and were severe in almost all cases. In the surfactant-treated group, epithelial lesions were absent in 12 , mild in 11 , and fairly prominent in two animals. We conclude that after treatment with surfactant, the premature newborn rabbit can be
\end{abstract}

Received May 10, 1984; accepted August 20, 1984.

Requests for reprints should be addressed to Roland Nilsson, M.D., Department of Pathology, St. Görans Hospital, S-112 81 Stockholm, Sweden.

This work was supported by the Swedish Medical Research Council (Project 3351), the Swedish National Association against Heart and Chest Diseases, the "Expressen" Prenatal Research Foundation, the Research Funds of the Karolinska Institute, and Allmänna Barnbördshusets Minnesfond. ventilated adequately with high frequency oscillation at comparatively low mean airway pressures and that surfactant replacement effectively reduces the development of epithelial lesions in conducting airways during high frequency oscillation. (Pediatr Res 19: 143-147, 1985)

\section{Abbreviations}

HFO, high frequency oscillation

$V_{T}$, tidal volume

$V_{v}$, volume density

The tendency of the surfactant-deficient lung to collapse at end-expiration can be compensated for by a variety of therapeutic measures, such as the application of continuous positive airway pressure (3) or the adjustment of respiratory rate and inspiration/ expiration ratio during artificial ventilation (6). Recent data from animal experiments and clinical trials indicate that ventilation by $\mathrm{HFO}$ might represent yet another realistic alternative (for review, see Refs. 1 and 5). During HFO, the lungs are kept expanded by the pressure needed to maintain uniform air expansion, while ventilation is provided by oscillatory movements involving tidal volumes smaller than the dead space of the airways. Gas exchange probably occurs by a combination of convection and diffusion, referred to as "augmented transport" (12). 
Ventilation of surfactant-deficient lungs with HFO might increase the risk of air leakage and pneumothorax if high mean airway pressure levels are required to prevent alveolar collapse (9). We have approached this problem by evaluating the combined effect of surfactant replacement and HFO in prematurely delivered newborn rabbits. In particular, we were interested in whether treatment with surfactant would improve survival and prevent the development of epithelial lesions during HFO, i.e. whether surfactant replacement would be as effective during HFO as during conventional positive pressure ventilation (10).

\section{MATERIALS AND METHODS}

Preparation of animals: surfactant replacement. We used 47 premature rabbit neonates delivered from seven does on day 27 of gestation (term = 31 days). The animals were obtained by hysterotomy during general anesthesia with sodium pentobarbital (Mebumal vet., $60 \mathrm{mg} / \mathrm{ml}$, ACO, Solna, Sweden). Immediately after birth, the neonates received an intraperitoneal injection of $0.1 \mathrm{ml}$ sodium pentobarbital (Mebumal vet., $60 \mathrm{mg} / \mathrm{ml}$, diluted $1: 10$ ). They were then tracheotomized in sequence, and in alternate animals a suspension of natural surfactant $(2 \mathrm{ml} / \mathrm{kg}$ body weight; phospholipid concentration $85-100 \mathrm{mg} / \mathrm{ml}$ ) was given in the tracheal cannula. In littermate controls the tracheal cannula was empty. Body weights $(\bar{x} \pm \mathrm{SD})$ of surfactant-treated animals and controls were $28 \pm 4$ and $27 \pm 3 \mathrm{~g}$, respectively.

Surfactant for these experiments was prepared from minced cow lungs by centrifugation $\left(3000 \times g, 4^{\circ} \mathrm{C}, 2 \mathrm{~h}\right)$, extraction with chloroform/methanol $2: 1(\mathrm{v} / \mathrm{v})$, and liquid-gel chromatography (Lipidex-5000). This procedure results in separation of the surfactant lipids into phospholipids, cholesterol, triglycerides, and cholesterylesters. The phospholipid fraction (which also contains approximately $1 \%$ protein) was used in the present experiment; its composition is shown in Table 1.

Ventilation. After tracheotomy, the animals were kept at $37^{\circ}$ $C$ in a multichambered, pressure-constant body-plethysmograph system (6). Before the onset of artificial ventilation, the plethysmographs were flushed with $100 \% \mathrm{O}_{2}$ and the neonates were allowed to breathe spontaneously. When the whole litter had been tracheotomized (duration of the tracheotomy procedure: 2-3 min 'animal) each neonate received an intraperitoneal injection of $0.1 \mathrm{ml}$ pancuronium bromide (Pavulon, $2 \mathrm{mg} / \mathrm{ml}$, Organon, Oss, Holland, diluted 1:10).

The animals were then ventilated in parallel for $60 \mathrm{~min}$ with $100 \% \mathrm{O}_{2}$. First, they were subjected for $30 \mathrm{~s}$ to conventional artificial ventilation (Servo Ventilator 900B, Siemens-Elema, Solns, Sweden) with an insufflation pressure of $35 \mathrm{~cm} \mathrm{H} \mathrm{H}_{2} \mathrm{O}$, a frequency of $40 / \mathrm{min}$, and $50 \%$ inspiration time, to promote uniform distribution of the exogenous surfactant within the lungs. Then the lungs were inflated for $30 \mathrm{~s}$ with a static pressure of $30 \mathrm{~cm} \mathrm{H}_{2} \mathrm{O}$. The pressure was then lowered to $6-8 \mathrm{~cm} \mathrm{H}_{2} \mathrm{O}$, and the animals were connected to a HFO unit (Siemens-Elema) generating a square pressure wave with frequency $15 \mathrm{~Hz}$ and $50 \%$ inspiration time at gas flow 2.5 liter $/ \mathrm{min}$. Insufflation pressure was recorded continuously with a pressure transducer (EMT 34, Siemens-Elema), $\mathrm{V}_{\mathrm{T}}$ with a differential pressure trans-

Table 1. Composition of phospholipids in the batch of bovine surfactant used in the present experiments

\begin{tabular}{lc}
\hline \multicolumn{1}{c}{ Phospholipids } & mol\% \\
\hline Phosphatidylcholine* & 68.7 \\
Phosphatidylethanolamine & 8.3 \\
Phosphatidylserine & 2.2 \\
Phosphatidylinositol & 2.7 \\
Phosphatidylglycerol & 3.8 \\
Lysophosphatidylcholine & 1.3 \\
Sphingomyelin & 8.2 \\
Other phospholipids & 4.8 \\
\hline
\end{tabular}

* Dipalmitoylphosphatidylcholine constitutes $33 \%$ of this fraction. ducer (EMT 32, Siemens-Elema) connected to the plethysmograph via a specially designed Fleisch tube (7). Tracings of insufflation pressure, $V_{\mathrm{T}}$, and $\mathrm{ECG}$ were obtained on a Mingograf 81 (Siemens-Elema). $V_{\mathrm{T}}$ of individual animals was defined as the mean of a randomly selected sequence of 10 volume oscillations. Recordings $<0.001 \mathrm{ml}$ were counted as 0 in our statistics.

In five litters, recordings of $\mathrm{V}_{\mathrm{T}}$ indicated gradual lung collapse in some $(n=6)$ of the surfactant-treated animals that had initially exhibited satisfactory volume oscillations (about $0.3 \mathrm{ml} / \mathrm{kg}$ ). HFO was then interrupted and a static insufflation pressure of $25 \mathrm{~cm} \mathrm{H}_{2} \mathrm{O}$ applied to all animals for $15 \mathrm{~s}$. After this "sigh," HFO was reestablished at the same mean airway pressure as before. The sigh maneuvre had to be repeated one to nine times to obtain a steady state.

Although a frequency of $15 \mathrm{~Hz}$ was generated by the ventilator unit, recordings of pressure and $\mathrm{V}_{\mathrm{T}}$ indicated that the lungs of the animals were, in fact, oscillating at a frequency of only $7-8$ $\mathrm{Hz}$. This discrepancy was caused by inertia in the water-seal used to maintain continuous distending airway pressure. During HFO, pressure in the ventilator system varied by $1-2 \mathrm{~cm} \mathrm{H}_{2} \mathrm{O}$ above and below the mean pressure level.

Histologic and morphometric techniques. After the experiment, the animals were killed by an intraperitoneal injection of Mebumal vet. $(0.5 \mathrm{ml})$. The abdomen of each animal was incised and the diaphragms inspected for evidence of pneumothorax. The chest was opened and a cannula was inserted into the pulmonary artery. The lungs were inflated with a pressure of $30 \mathrm{~cm} \mathrm{H}_{2} \mathrm{O}$ for $30 \mathrm{~s}$. The endotracheal pressure was then lowered and maintained at $10 \mathrm{~cm} \mathrm{H}_{2} \mathrm{O}$ for $15 \mathrm{~min}$, while the pulmonary artery was perfused with a mixture of $1 \%$ glutaraldehyde and $3.5 \%$ formaldehyde at a pressure of $70 \mathrm{~cm} \mathrm{H}_{2} \mathrm{O}$. After perfusion, the lungs were removed and kept in $10 \%$ formalin for at least $24 \mathrm{~h}$.

Paraffin sections from the basal parts of both lungs were stained with hematoxylin and eosin and examined microscopically. The relative volume of the alveolar spaces, the alveolar $V_{v}$, was determined by point-counting. The same sections were reexamined at high power for evidence of bronchiolar epithelial lesions.

Statistical evaluation. The $\chi^{2}$ test and the Wilcoxon twosample test (two-tailed) were used in our statistical calculations.

\section{RESULTS}

Survival. According to ECG recordings, only one of the 22 control animals survived the period of ventilation. By contrast, 23 of 24 surfactant-treated neonates (ECG could not be recorded in one animal) had regular cardiac activity at the end of the experiment ( $p<0.001$; Fig. 1). Cardiac frequency of surviving surfactant-treated animals was $217 \pm 40 / \mathrm{min}(\overline{\mathrm{x}} \pm \mathrm{SD})$.

$V_{T}$. At all intervals, $\mathrm{V}_{\mathrm{T}}$ was significantly higher in surfactanttreated animals than in controls (Fig. 1, Table 2). This was also obvious from direct inspection: the chest of most surfactanttreated animals vibrated vigorously while the controls exhibited no visible movements. Average $\mathrm{V}_{\mathrm{T}}$ in surfactant-treated animals was about $15 \%$ of the estimated dead space, $2.2 \mathrm{ml} / \mathrm{kg}$ (13).

Complications. Postmortem examination revealed pneumothorax in two surfactant-treated animals; no such complication was observed in controls.

Histologic and morphometric findings. The lungs of surfactanttreated animals were generally well expanded and contained only small amounts of fluid in the alveolar spaces. The rounded configuration of alveoli indicated that they were air-expan-led (Fig. $2 A$ ). In control animals, the lungs were largely collapsed with wrinkled, fluid-filled alveoli (Fig. $2 B$ ). Alveolar $V_{\mathrm{v}}$ was significantly higher in surfactant-treated animals than in controls (Table 3).

Bronchiolar epithelial lesions were absent in 12 of the surfactant-treated animals (Fig. $3 A$ ), mild in 11 , and fairly prominent in two. The six animals that had to be "sighed" repeatedly to maintain satisfactory volume oscillation, and the two animals 
Control<smiles>CCCCCCCCCCCCCCCCCCCCCCCCCO[O+]([O-])O</smiles>

${ }_{0.01 \mathrm{ml}}$ I UW

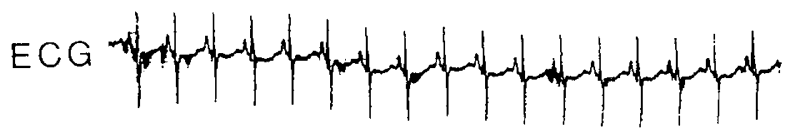

$1 \mathrm{sec}$

Fig. 1. Recordings of $V_{T}$ and ECG after $60 \mathrm{~min}$ of HFO. In the control animal (upper panel), volume oscillations are barely detectable; this animal had no cardiac activity in simultaneous ECG recordings (not shown). In the surfactant-treated animal (middle and lower panels), the average volume oscillation amounts to $0.008 \mathrm{ml}(0.33 \mathrm{ml} / \mathrm{kg})$ and there is regular cardiac activity (frequency $234 / \mathrm{min}$ ). that developed pneumothorax, all belonged to the group of surfactant-treated animals showing mild or fairly prominent epithelial lesions.

All but one of the control animals displayed extensive necrosis and desquamation of bronchiolar epithelium with abundant hyaline membranes (Fig. $3 B$, Table 3 ). In the remaining contro! similar, but less prominent, lesions were observed.

\section{DISCUSSION}

Judged from our recordings of in vivo lung mechanics and ECG, treatment with surfactant increases $V_{T}$ and survival in premature rabbit neonates ventilated with HFO. These benefits

Table 2. $V_{T}(\bar{x}$ and range; $\mathrm{ml} / \mathrm{kg}$ ) at various time intervals after onset of HFO, in surfactant-treated animals and controls

\begin{tabular}{ccccc}
\hline & \multicolumn{4}{c}{ Time intervals (min) } \\
\cline { 2 - 5 } Treatment & 15 & 30 & 45 & 60 \\
\hline Surfactant $(n=25)$ & 0.35 & 0.37 & 0.37 & 0.35 \\
& $(0-0.58)^{*}$ & $(0-0.80)$ & $(0-1.04)$ & $(0-0.84)$ \\
Controls $(n=22)$ & 0.01 & 0.04 & 0.04 & 0.03 \\
& $(0-0.10)$ & $(0-0.13)$ & $(0-0.15)$ & $(0-0.18)$ \\
$p<$ & 0.005 & 0.005 & 0.005 & 0.005 \\
\hline
\end{tabular}

* In surfactant-treated animals with intermittent lung collapse $\left(\mathrm{V}_{\mathrm{T}}=\right.$ 0 ), satisfactory volume oscillations could be restored by "sighing" (see "Materials and Methods").

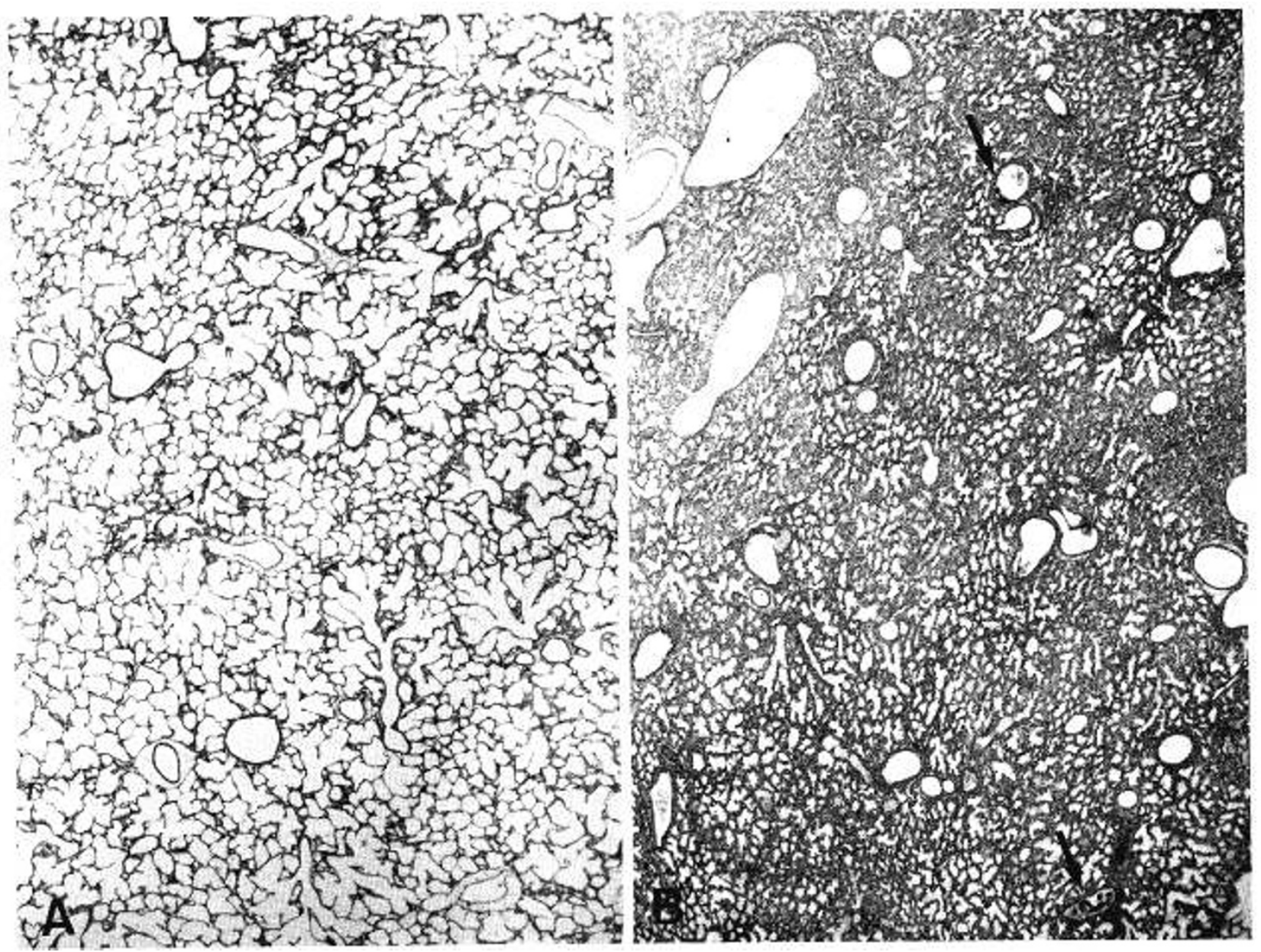

Fig. 2. Low-power fields of lung sections, showing the effect of surfactant replacement on the alveolar expansion pattern after 60 min of HFO. In the surfactant-treated animal $(A)$, alveoli are well air-expanded and no epithelial lesions are found. In the control animal $(B)$, the alveoli are clearly less expanded and, in fact, are largely fluid-filled. Hyaline membranes are seen in some bronchioles (arrows). Hematoxylin and eosin, $\times 30$. 
of surfactant replacement are similar to those previously documented in premature newborn rabbits during spontaneous (8) or artificial ventilation (10). Our data are also in agreement with findings reported by Takada et al. (14) who found, in experiments on lung-lavaged adult rabbits, that the effects of surfactant nebulization during high frequency jet ventilation were equivalent to those of surfactant instillation during conventional positive pressure ventilation.

The mean airway pressure used in the present experiments, 6$8 \mathrm{~cm} \mathrm{H}_{2} \mathrm{O}$, was too low to ensure air expansion of the lungs in control animals, yet it was high enough to allow the development of bronchiolar epithelial lesions. Surfactant-treated animals ventilated with the same mean airway pressure had mostly wellexpanded lungs, with significantly less epithelial lesions. This suggests that the epithelial lesions do not result simply from "barotrauma," but from a disturbance of the normal expansion pattern of alveoli and bronchioles. Since the length and diameter of the bronchioles depend on the degree of expansion of sur-

Table 3. $V_{V}(\bar{x} \pm S D)$ and incidence of bronchiolar epithelial lesions after $60 \mathrm{~min}$ of HFO in surfactant-treated animals and controls

\begin{tabular}{lccc}
\hline & & \multicolumn{2}{c}{ No. of animals } \\
\cline { 3 - 4 } Treatment & $\mathrm{V}_{\mathrm{v}}$ & With lesions & Without lesions \\
\hline Surfactant & $0.65 \pm 0.08$ & 13 & 12 \\
Controls & $0.37 \pm 0.08$ & 22 & 0 \\
$p<$ & 0.005 & \multicolumn{2}{c}{0.001} \\
\hline
\end{tabular}

rounding alveoli (4), shear forces develop in a lung that is not uniformly expanded. These forces might lead to necrosis and desquamation of bronchiolar epithelium within a few minutes of spontaneous (2) or artificial ventilation (11). If surfactantdeficient lungs are subjected to HFO with a mean airway pressure that is too low to keep the alveoli open, the same pathogenic mechanism is triggered and epithelial lesions would tend to occur proximal to air-liquid interfaces "rattling" in terminal bronchioles.

Treatment with surfactant probably protects against airway epithelial lesions by holding the air-liquid interface at alveolar level throughout the ventilatory cycle, and by promoting uniform alveolar expansion. The bronchioles are then stabilized by surrounding aerated alveoli. Some epithelial lesions were observed in all the six surfactant-treated animals that had to be "sighed" to avoid gradual lung collapse. These animals obviously needed a mean airway pressure higher than that required to maintain stable lung aeration in other surfactant-treated littermates. Individual adjustment of mean airway pressure (a prerequisite for adequate clinical management of patients with severe surfactant deficiency) was not feasible in the present system for "collective" artificial ventilation.

In these experiments, mean airway pressure was adjusted to maintain adequate oscillatory volume in surfactant-treated animals, whereas the lungs of control animals were oscillated in a nearly collapsed state. Our data do not provide evidence whether, in control animals, epithelial lesions would be less prominent if the alveoli had been kept open with a higher mean airway pressure. It may be concluded, however, that after treatment

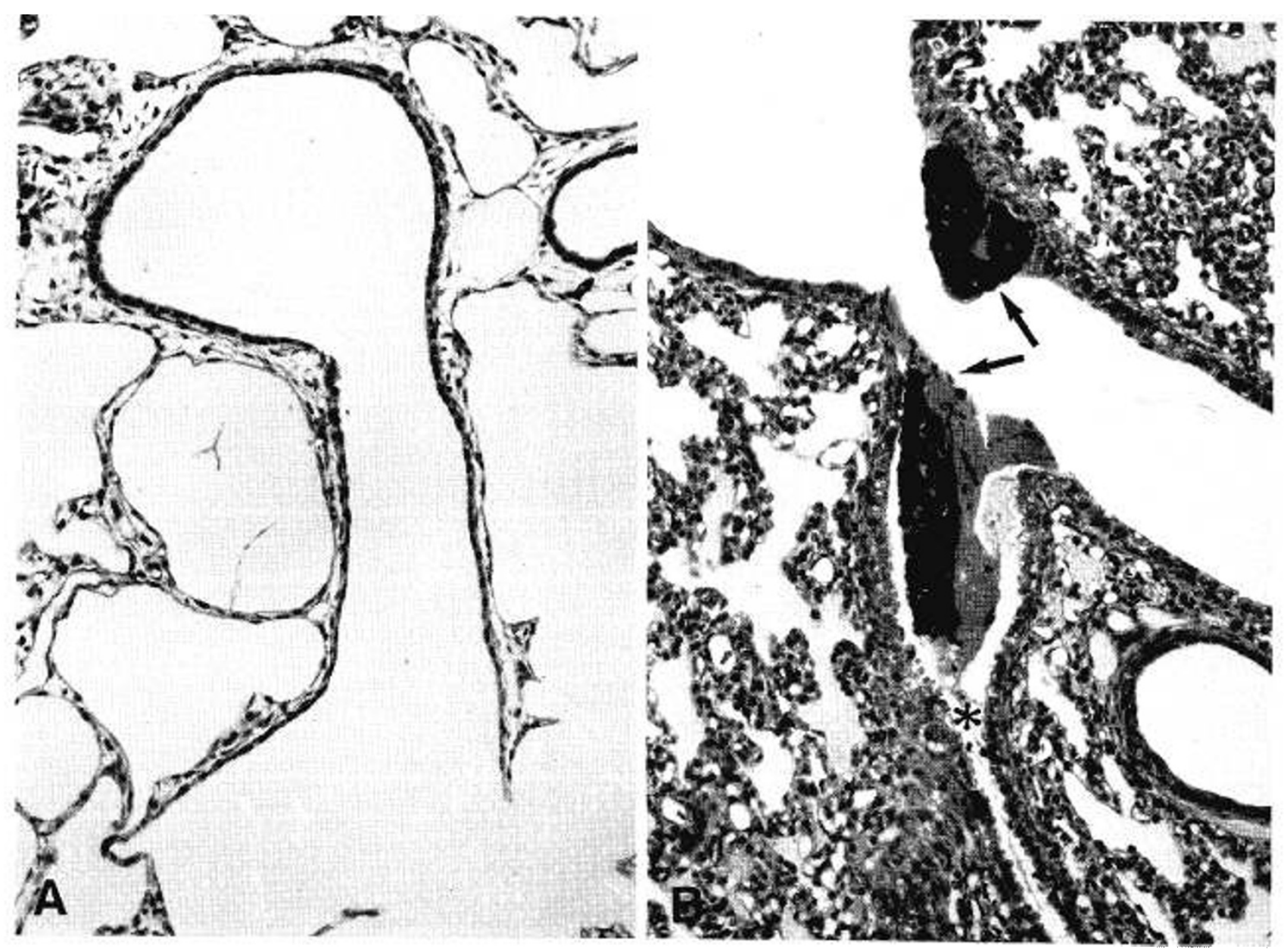

Fig. 3. High-power fields of bronchioles documenting the beneficial effect of surfactant replacement. In the surfactant-treated animal $(A)$, a wellaerated bronchiole is coated with intact, flattened epithelium. In the control $(B)$, the bronchiole indicated by an asterisk is obviously nonaerated, whereas the more proximal airway is aerated, with denuded surface. The terminal bronchioles of the control animal contain clusters of necrotic, desquamated epithelium (arrows). Hematoxylin and eosin, $\times 300(A), \times 280(B)$. 
with exogenous surfactant, the premature rabbit lung can be ventilated adequately with $\mathrm{HFO}$ at a comparatively low mean airway pressure, and that at these particular experimental conditions surfactant replacement effectively prevents the development of epithelial lesions.

Acknowledgments. We are indebted to Dr. Charles A. Bryan, Toronto, for constructive criticism during pilot experiments preceding this study, and Dr. Stellan Bygdeman, Stockholm, for valuable advice concerning the interpretation of the ECG recordings.

\section{REFERENCES}

1. Bland RD, Sedin EG 1983 High frequency mechanical ventilation in the treatment of neonatal respiratory distress. Int Anesthesiol Clin 21:125-147

2. Finlay-Jones J-M, Papadimitriou JM, Barter RA 1974 Pulmonary hyaline membrane: light and electron microscopic study of the early stage. J Pathol 112:117-124

3. Gregory GA, Kitterman JA, Phibbs RH, Tooley WH, Hamilton WK 1971 Treatment of the idiopathic respiratory distress syndrome with continuous positive airway pressure. N Engl J Med 284:1333-1340

4. Hughes JMB, Hoppin FG, Mead J 1972 Effect of lung inflation on bronchiolar length and diameter in excised lungs. J Appl Physiol 32:25-35
5. Jobe A 1984 Respiratory distress syndrome-new therapeutic approaches to a complex pathophysiology. Adv Pediatr 30:93-130

6. Lachmann B, Grossmann G, Freyse J, Robertson B 1981 Lung-thorax compliance in the artificially ventilated premature rabbit neonate in relation to variations in inspiration:expiration ratio. Pediatr Res 15:833-838

7. Lachmann B, Grossmann G, Nilsson R, Robertson B 1979 Lung mechanics during spontaneous ventilation in premature and fullterm rabbit neonates. Respir Physiol 38:283-302

8. Lachmann B, Grossmann G, Nilsson R, Robertson B 1981 Effect of supplementary surfactant on in vivo lung mechanics in the premature rabbit neonate. Eur J Pediatr 136:173-179

9. Mautone AJ, lorio P, Moss IR, Scarpelli EM 1982 Use of high frequency oscillation in immature lambs at birth. Pediatr Res 16:356A

10. Nilsson R, Grossmann G, Robertson B 1978 Lung surfactant and the pathogenesis of neonatal bronchiolar lesions induced by artificial ventilation. Pediatr Res 12:249-255

11. Nilsson R, Grossmann G, Robertson B 1980 Bronchiolar epithelial lesions induced in the premature rabbit neonate by short periods of artificial ventilation. Acta Pathol Microbiol Scand (A) 88: 359-367

12. Slutsky AS, Brown R, Lehr J, Rossing T, Drazen JM 1981 High-frequency ventilation: a promising new approach to mechanical ventilation. Med Instrum 15:229-233

13. Strang LB 1977 Neonatal respiration. Physiological and clinical studies. Blackwell Scientific Publications, Oxford, p 69

14. Takada Y, Kobayashi T, Kataoka H, Murakami S, Kokubo M, Yoshida T 1983 Effects of surfactant supplement by high frequency jet ventilation in lung lavaged rabbits. J Jpn Med Soc Biol Interface 14:67-74

\title{
Rheology of Fetal and Maternal Blood
}

\author{
WALTER H. REINHART, STUART J. DANOFF, ROBERT G. KING, AND SHU CHIEN \\ Division of Circulatory Physiology and Biophysics, Department of Physiology, and Division of Neonatal \\ Medicine, Department of Pediatrics, Columbia University College of Physicians and Surgeons,
} New York, New York 10032

\begin{abstract}
Rheological parameters were measured in 10 pairs of mothers and newborns. Whole blood viscosity was similar despite a higher fetal hematocrit $(47.0 \pm 5.1$ versus $35.5 \pm 12.0 \%$, mean $\pm \mathrm{SD}, p<0.05$ ). When the hematocrit of the suspension of red cells in plasma was adjusted to $45 \%$, the viscosity was significantly lower in the fetal blood over a wide range of shear rates $(0.52-208$ $\mathrm{s}^{-1}$ ). The main reason for the lower viscosity in the fetal blood was the lower plasma viscosity as compared to the maternal blood $(1.08 \pm 0.05$ versus $1.37 \pm 0.08$ centipoise, $p<0.05)$; this in turn was attributable to a lower total plasma protein concentration $(4.74 \pm 0.71$ versus $6.47 \pm$ $0.64 \mathrm{~g} / \mathrm{dl}, p<0.05)$. All protein fractions were lower in the fetal plasma. The assessment of red cell deformability by filtration through polycarbonate sieves revealed that the resistance of a fetal red cell was three times higher than that of a maternal red cell in a $2.6-\mu \mathrm{m}$ pore, but there was no significant difference in resistance for these red cells in 6.9- $\mu \mathrm{m}$ pores. This higher filtration resistance of fetal red
\end{abstract}

Received November 4, 1983: accepted July 6, 1984

Correspondence may be addressed to Dr. S. Chien, Department of Physiology, Columbia Medical Center, 630 West 168th Street, New York, NY 10032.

This research was supported in part by United States Public Health Service Research Grant HL-16851 from the National Heart, Lung, and Blood Institute, the Schweizerische Stiftung fuer Medizinisch-Biologische Stipendien, and the Heart Research Foundation, New York. cells through the small pores was mainly due to their large volume (115.4 \pm 10.8 versus $93.5 \pm 5.9 \mathrm{fl}, p<0.001)$. Measurements on membrane-free hemoglobin solutions indicated that the internal viscosity of these two types of red cells was not different. We conclude that in fetal blood the higher hematocrit and the presence of larger red cells, which cause impaired passage through pores $<5 \mu \mathrm{m}$, are counterbalanced by a decreased plasma viscosity, resulting in a whole blood viscosity comparable to that of adults. (Pediatr Res 19:147-153, 1985)

\section{Abbreviations}
Het, hematocrit
RBC, red blood cell
WBC, white blood cell
MCV, mean corpuscular volume
MCH, mean corpuscular hemoglobin
MCHC, mean corpuscular hemoglobin concentration
$\mathrm{cP}$, centipoise

Hyperviscosity syndrome in neonates is a serious condition, which may cause congestive heart failure, respiratory distress, and cyanosis $(13,24)$, cerebral infarction (2) and necrotizing 